\title{
Access to healthy food retailers among formerly incarcerated individuals
}

\author{
Alexander M Testa* \\ Department of Criminal Justice, University of Texas at San Antonio, 501 W. Cesar E. Chavez Blvd, San Antonio, \\ TX 78207, USA
}

Submitted 4 June 2018: Final revision received 3 August 2018: Accepted 13 September 2018: First published online 23 October 2018

\begin{abstract}
Objective: To assess access to healthy food retailers among formerly incarcerated individuals.

Design: Using linked data from the National Longitudinal Study of Adolescent to Adult Health and the Modified Retail Food Environment Index, the present study applies multivariate logistic regression to assess the association between incarceration and (i) living in a food desert and (ii) having low access to healthy food retailers. To account for unobserved heterogeneity, additional analyses are performed comparing formerly incarcerated individuals with persons arrested or convicted for a crime but not previously incarcerated.

Setting: Sample of respondents living in urban census tracts in the USA.

Subjects: Adults ( $n$ 10390) aged 24-34 years.

Results: In adjusted logistic regression models, prior incarceration was not significantly associated with living in a food desert (OR $=1.097$; 95\% CI 0.896, 1.343). Prior incarceration significantly increased the likelihood of living in a census tract with low access to healthy food retailers (OR $=1 \cdot 265$; 95\% CI 1.069, 1.498). This significant association remained when comparing formerly incarcerated individuals with those who had been arrested or convicted of a crime, but not previously incarcerated $(\mathrm{OR}=1 \cdot 246 ; 95 \%$ CI $1 \cdot 032,1 \cdot 503)$.

Conclusions: Formerly incarcerated individuals are more likely to live in areas with low access to healthy food retailers compared with their non-incarcerated counterparts. Because lower access healthy food retailers may be associated with worse health and dietary behaviour, disparities in local food retail environments may exacerbate health inequalities among formerly incarcerated individuals.
\end{abstract}

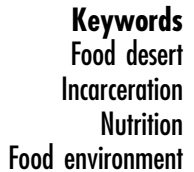

Approximately 30 million Americans reside in an area that lacks access to affordable nutritious food ${ }^{(1)}$. Characteristics of the built environment, such as geographic accessibility of food retailers, are important for understanding health disparities as individuals typically make dietary decisions based on which food outlets are available in their local neighbourhoods ${ }^{(2)}$. Indeed, persons residing in areas with access to healthy food retailers tend to have healthier dietary patterns ${ }^{(3,4)}$ and a lower prevalence of obesity and other diet-related disease ${ }^{(5-8)}$. In contrast, individuals living in areas predominantly composed of unhealthy food retailers, such as fast-food restaurants, often have poorerquality diets marked by greater consumption of fast foods and other high-energy, nutrient-poor foods ${ }^{(9,10)}$, as well as a higher prevalence of obesity ${ }^{(11,12)}$.

The definition of 'food deserts' varies in prior literature, but in general are considered geographic areas that lack access to healthy food retailers, such as a supermarket or grocery store ${ }^{(13)}$. Communities that contain healthy food retailers, but have a substantially higher ratio of unhealthy food retailers that sell high-energy-dense foods relative to healthy food retailers, are labelled 'food swamps ${ }^{(14,15)}$. In the USA, neighbourhoods characterized by economic deprivation and minority composition tend to have fewer healthy food retailers and a higher prevalence of unhealthy food retailers ${ }^{(3,16-18)}$. However, an examination of local food retail environments among certain disadvantaged segments of the population has gone overlooked by prior research. Notably, no research to date has studied access to healthy food retailers among formerly incarcerated individuals.

The US incarceration rate has quadrupled since the $1970 \mathrm{~s}^{(19)}$, leaving the number of formerly incarcerated individuals large enough to be considered a 'felon class, ${ }^{(20)}$. Indeed, each year approximately 600000 individuals leave state and federal prisons and millions exit 
local jails ${ }^{(21,22)}$. Although individuals entering into prisons or jails already exhibit several markers of disadvantage including low levels of human, financial and social capital, contact with the correctional system can alter one's life course and exacerbate disadvantage ${ }^{(23)}$. In particular, incarceration is associated with poorer health status ${ }^{(24)}$, worse health behaviour ${ }^{(25)}$, living in disadvantaged communities $^{(26)}$ and difficulty meeting basic material needs ${ }^{(27)}$. Moreover, the high prevalence of incarceration in the USA may play a role in shaping inequalities in health ${ }^{(24)}$.

While past research often notes that communities where formerly incarcerated individuals return to are deficient in resources $^{(28)}$, limited research investigates what types of resources are lacking in these areas. Examining the association between prior incarceration and post-release access to food retailers is important for three primary reasons. First, since individuals with better access to healthy food retailers consume healthier diets marked by higher intakes of fresh fruits and vegetables, fresh meats and other nonprocessed foods $^{(4,17,29,30)}$, local food retail environments may be an important factor in understanding the association between prior incarceration and health outcomes. Second, there is reason to expect that prior incarceration may worsen access to healthy food retailers as incarceration increases economic hardship and negatively affects neighbourhood attainment ${ }^{(26,27)}$, which are associated with having lower access to healthy food retailers (i.e. supermarket, grocery stores), as well as greater access to unhealthy food retailers (i.e. fast-food restaurants, convenience stores $)^{(3,13,16,31)}$. Finally, research on food environments and health outcomes ${ }^{(32)}$ and the consequences of incarceration for health ${ }^{(24)}$ has greatly expanded in recent years, yet no prior research has united these two fields.

The current study provides the first examination of the relationship between prior incarceration and local food retail environments in areas where formerly incarcerated individuals reside. The study is carried out in three stages. First, the association between prior incarceration and accessibility to healthy food retailers is estimated. Next, a formal mediation analysis is used to assess the degree to which this association is explained by concentrated disadvantage of the census tract where formerly incarcerated individuals live. Finally, to reduced unobserved heterogeneity, an additional analysis is conducted that compares formerly incarcerated individuals with those who have been previously arrested or convicted for a crime but not incarcerated. Using this strategic comparison group helps account for unobserved heterogeneity that may bias the association between incarceration and access to healthy food retailers ${ }^{(25)}$.

\section{Methods}

The current study links two sources of data. The primary source of data came from waves I and IV of the National
Longitudinal Study of Adolescent to Adult Health (Add Health), a nationally representative survey of adolescents enrolled in grades 7-12 in the USA during the 1993/94 academic year $^{(33)}$. At wave I, 90000 students at 132 schools were surveyed. Following the initial survey, approximately 20000 individuals were selected for in-home interviews. To date, three interviews have been conducted since the initial survey: wave II administered in 1996; wave III administered in 2001-2002; and wave IV conducted in 2008. At wave IV, 15701 respondents completed interviews.

Second, data were obtained from the Modified Retail Food Environment Index (mRFEI), a national measure of food retailers compiled by Centers for Disease Control and Prevention (CDC) in 2008-2009 ${ }^{(34)}$. The mRFEI data were collected for 65345 US census tracts and include information on over one million food retailers. The mRFEI score ranges from 0 to 100 and captures the ratio of healthy to unhealthy food retailers in a census tract and the $0.8 \mathrm{~km}(0.5$ mile $)$ buffer around a census tract. Food retailers are defined using the North American Industry Classification System (NAICS). Healthy food retailers include supermarkets (NAICS 445100), larger grocery stores (NAICS 445100), fruit and vegetable markets (NAICS 445230) and warehouse clubs (NAICS 452910). The CDC obtained data on healthy food retailers from the InfoUSA business database, 2009. Unhealthy food retailers include fast-food restaurants (NAICS 722211), small grocery stores (NAICS 44511) and convenience stores (NAICS 445120). Data on convenience stores were from the Homeland Security Information Program database, 2008 and data on small grocery stores and fast-food restaurants were collected from the NavTeq database, 2009.

The use of healthy-to-unhealthy food retailer ratios provides some benefits over alternative measures, such as those that consider the count or density of specific food retailers (i.e. supermarkets), because healthy and less healthy food retailers can be correlated within geographical units ${ }^{(35)}$. Accordingly, neighbourhood food environments are more complex than the total number of healthy or unhealthy food retailers within a neighbourhood, as there are areas that both contain healthy and unhealthy food retailers, both of which influence dietary patterns of residents. Moreover, recent research also suggests that measures of relative healthy-to-unhealthy food access provide a stronger measure of food purchasing and consumption behaviours compared with measures of absolute densities of healthy or unhealthy food outlets $^{(35,36)}$.

The mRFEI data were linked to 15696 census tracts at wave IV of the Add Health survey though the ancillary studies in the Add Health programme. As prior research finds the $0.8 \mathrm{~km}(0.5$ mile) buffer from census tract of residence used by the $\mathrm{CDC}$ is an appropriate method for classifying access to food retailers in urban areas, the analysis restricts the sample to Add Health respondents who reside in urban census tracts at wave IV 
(n 11509) $)^{(37)}$. Urban census tracts are identified using Rural-Urban Community Areas (RUCA) codes. Further, because of missing data as a result of non-response, the final analytic sample size is 10390 .

\section{Measures}

\section{Healthy food access}

Healthy food access is measured in two ways. 'Food desert' is a binary indictor of census tracts with an mRFEI score of 0 . According to the CDC these areas are consistent with the concept of a food desert (i.e. an area where there is no access to healthy food retailers) ${ }^{(34)}$. 'Low access to healthy food retailers' is binary indicator for census tracts with an mRFEI score less than 10. This threshold was selected because an mRFEI score lower than 10 is below the national average and has been shown by prior research to be associated with lower-quality nutrition ${ }^{(34,35,38,39)}$.

\section{Incarceration}

'Prior incarceration' is coded as a binary variable indicating whether or not a respondent had previously spent time in jail, prison or other correctional facility at age 18 years or older by wave IV.

\section{Controls}

Several characteristics that may confound the relationship between incarceration and access to food retailers are included as control variables. 'Age' is a continuous measure of the respondent's age at wave IV. 'Race/ethnicity' is coded as a series of binary measures indicating whether the respondent identified as White, Black, Hispanic or Other race. 'Sex' is a binary indicator where 1 equals male and 0 equals female. 'Child in home' is a binary indicator for respondents with a child living in their household. 'High school degree' is a binary variable indicating whether or not the respondent completed high school by wave IV. 'Child abuse victim' measures whether a respondent reported being hit with a fist, kicked, thrown down to the floor, into a wall or down the stairs by a parent or adult caregiver before their 18th birthday. 'Parent house' measures whether a respondent reported living with his/her parents at wave IV. 'Total delinquency' is a scale measured at wave I, including involvement in vandalism, shoplifting, theft, burglary, fighting, selling drugs, robbery and assaulting someone with a weapon $(\alpha=0.85)$. 'Hard drug use' is a binary measure for whether a respondent reported any illegal drug use besides marijuana at wave I. 'Healthy diet' measures the number of times a respondent ate fruits or vegetables the day before his/her wave I interview. 'Depression' is a scale measured at wave I where respondents were asked on a scale of 0 to 3 how often they experienced each of the following during the prior week: being bothered by things that don't usually bother you; not feeling like eating; appetite was poor; could not shake off the blues; feel like you were as good as other people (reverse coded); felt depressed; felt too tired to do things; felt hopeful (reverse coded); felt like a failure; enjoyed life (reverse coded); felt sad; and felt life was not worth living $(\alpha=0 \cdot 82)$. 'Fatalism' measures a respondent's perceived likelihood of living to age 35 years at wave I. 'Concentrated disadvantage' is generated using a standardized scale that captures the proportion of residents within a respondent's census tract who are on welfare, living at or below the poverty line, are unemployed, and the proportion of female-headed households. A measure of concentrated disadvantaged is included as a control variable at wave I $(\alpha=0.93)$ and a mediator variable at wave IV $(\alpha=0 \cdot 81)$.

\section{Analytic strategy}

The analyses are conducted using the statistical software package Stata version 15.0 and all estimates use survey weights to account for the multistage cluster design of the Add Health survey. The study applies multivariate logistic regression analysis and controls for characteristics that are related to incarceration and access to food retailers. Model 1 presents a bivariate model that predicts access to healthy food retailers using prior incarceration. Model 2 adjust for all covariates except wave IV concentrated disadvantage. Model 3 adds the variable measuring wave IV concentrated disadvantage. While ruling out selection effects is not entirely possible, Model 4 aims to reduce unobserved heterogeneity by changing the comparison category to respondents who have been arrested or convicted, but not previously incarcerated ${ }^{(25)}$. Variance inflation factor values for all models were below 3, indicating no issues related to multicollinearity ${ }^{(40)}$.

Finally, a mediation analysis is conducted using the Karlson-Holm-Breen (KHB) test for mediation in nonlinear models to assess the percentage change in the incarceration coefficient attributed to concentrated disadvantage at wave $\mathrm{IV}^{(42)}$. Coefficients across nested logistic regression models cannot be directly compared because there is a rescaling of the model that occurs whenever a variable that has an independent effect on the dependent variable is added to a model, whether or not an individual variable is correlated with other independent variables in the model ${ }^{(42)}$. The benefit of the KHB method is that it accounts for the rescaling that occurs when additional variables are included in the model. The KHB test indicates whether any difference in the prior incarceration coefficient between the reference model (not including mediators) and the full model (including mediators) is significantly different from chance.

\section{Results}

Table 1 provides the descriptive statistics for the analytic sample. At wave IV the sample was 28 years old on 
average. Slightly less than half the sample was male (49.5\%) The sample was mostly White (65.2\%); about $14.6 \%$ was Black, $14.9 \%$ Hispanic, and $5.3 \%$ was classified as Other race. In total, $14.2 \%$ of the sample had been incarcerated as an adult by wave IV. About $16.3 \%$ of respondents lived in food deserts $(\mathrm{mRFEI}=0)$ and $52 \cdot 1 \%$ of respondents lived in a census tract with low access to healthy food retailers $(\mathrm{mRFEI}<10)$. Table 2 displays the differences in the outcome variables across those who had been previously incarcerated and those who had not. Relative to those who had not been previously incarcerated, formerly incarcerated individuals were not significantly more likely to reside in food deserts $(18.5 \%$ v. $16.0 \% ; P=0.106$ ). Formerly incarcerated respondents were significantly more likely to live in areas with low access to healthy food retailers compared with respondents who had not been previously incarcerated (58.7 v. $50.9 \% ; P<0.001$ ), as well as compared with respondents who had been arrested or convicted, but not incarcerated (58.7 v. 51.5\%; $P=0.003)$.

Table 3 presents the results of the logistic regression model that estimates access to healthy food retailers as a function of prior incarceration. Model 1 in Table 3(a), which presents the unadjusted association, demonstrates that formerly incarcerated individuals, in comparison to those who had not been previously incarcerated, did not differ significantly in the likelihood of living in a food desert (OR $=1.196 ; 95 \%$ CI 0.968, 1.479). The results of Model 1 in Table 3(b) demonstrate that formerly incarcerated individuals were significantly more likely to live in a census tract with low access to healthy food retailers (OR $=1 \cdot 366 ; 95 \%$ CI 1.150, 1.622).

Model 2 adjusts for covariates that may confound the association between prior incarceration and access to food retailers. The results of Model 2 in Table 3(a) illustrate that prior incarceration had a positive but not statistically significant association with living in a food desert ( $\mathrm{OR}=$ 1.148; 95\% CI 0.938, 1.406). Model 2 in Table 3(b) indicates that prior incarceration had a positive and statistically significant association with having low access to healthy food retailers $(\mathrm{OR}=1.323 ; 95 \%$ CI 1.117, 1.567).

Model 3 in Table 3(a) shows that after adjusting for concentrated disadvantage measured at wave IV, the magnitude of the association between prior incarceration and living in a food desert was reduced $(\mathrm{OR}=1.097 ; 95 \%$ CI 0.896, 1.343). Similarly, Model 3 in Table 3(b) demonstrates that the association between prior incarceration and low access to healthy food retailers reduced in magnitude but remained positive and statistically significant (OR= 1.265; $95 \%$ CI 1.069, 1.498). The measure of concentrated disadvantage at wave IV had a positive association with living in a food desert (OR $=2 \cdot 031 ; 95 \%$ CI 1.397, 2.952) and having low access to healthy food retailers ( $O R=$ 2.466; $95 \%$ CI 1.898, 3.203). The KHB analysis indicates concentrated disadvantage reduced the association between prior incarceration and food deserts by $31 \%$ $(t=3.258, \quad P<0.001)$ and low access to healthy food retailers by $18.5 \%(t=3.569, P<0.001)$. Finally, to reduce unobserved heterogeneity, Model 4 restricts the reference category to respondents who reported being previously

Table 1 Descriptive statistics for variables used in the analysis: National Longitudinal Study of Adolescent to Adult Health (waves I \& IV) and Modified Retail Food Environment Index (mRFEI)

\begin{tabular}{|c|c|c|c|c|}
\hline Variables & Mean & SE & Minimum & Maximum \\
\hline \multicolumn{5}{|l|}{ Dependent variables } \\
\hline Food desert $(\mathrm{mRFEI}=0)$ & 0.163 & 0.010 & 0 & 1 \\
\hline Low access to healthy food (mRFEI $<10)$ & 0.521 & 0.014 & 0 & 1 \\
\hline \multicolumn{5}{|l|}{ Independent variable } \\
\hline Prior incarceration & 0.142 & 0.008 & 0 & 1 \\
\hline \multicolumn{5}{|l|}{ Control variables } \\
\hline Age (W4) & 28.44 & 0.129 & 24 & 34 \\
\hline White & 0.652 & 0.032 & 0 & 1 \\
\hline Black & 0.146 & 0.020 & 0 & 1 \\
\hline Hispanic & 0.149 & 0.021 & 0 & 1 \\
\hline Other race & 0.053 & 0.008 & 0 & 1 \\
\hline Male & 0.497 & 0.009 & 0 & 1 \\
\hline Child in home (W4) & 0.169 & 0.010 & 0 & 1 \\
\hline Parent house (W4) & 0.145 & 0.009 & 0 & 1 \\
\hline High school (W4) & 0.920 & 0.009 & 0 & 1 \\
\hline Child abuse (W4) & 0.184 & 0.007 & 0 & 1 \\
\hline Total delinquency (W1) & 2.593 & 0.080 & 0 & 38 \\
\hline Hard drug use (W1) & 0.125 & 0.008 & 0 & 1 \\
\hline Healthy diet (W1) & 0.909 & 0.005 & 0 & 1 \\
\hline Depression (W1) & 6.497 & 0.110 & 0 & 33 \\
\hline Fatalism (W1) & 1.567 & 0.019 & 1 & 5 \\
\hline Concentrated disadvantage (W1) & -0.081 & 0.077 & -1.199 & $7 \cdot 865$ \\
\hline \multicolumn{5}{|l|}{ Mediator variable } \\
\hline Concentrated disadvantage (W4) & -0.020 & 0.019 & -0.616 & $2 \cdot 619$ \\
\hline
\end{tabular}

W1, wave I; W4, wave IV.

The sample size is 10390 . 
Table 2 Percentage of respondents living in food deserts and with low access to healthy food retailers by incarceration status in the sample of adults $(n 10390)$ aged $24-34$ years living in urban census tracts in the USA, 2008

\begin{tabular}{lccc}
\hline Variables & $\begin{array}{c}\text { Prior incarceration } \\
(n \text { 1394 })\end{array}$ & $\begin{array}{c}\text { No prior incarceration } \\
(n \text { 8996) }\end{array}$ & $\begin{array}{c}\text { Arrested/convicted, not incarcerated } \\
(n \text { 1478) }\end{array}$ \\
\hline Food desert $(\mathrm{mRFEI}=0)$ & 18.5 & 16.0 & 17.4 \\
Low access to healthy food $(\mathrm{mRFEI}<10)$ & 58.7 & $50 \cdot 9^{\star \star *}$ & $51.5^{\star *}$ \\
\hline
\end{tabular}

mRFEI, Modified Retail Food Environment Index.

Statistically significant difference compared with the prior incarceration category: ${ }^{\star \star} P<0.01,{ }^{\star \star \star} P<0.001$.

Table 3 Results of logistic regression models for the association of living in a food desert and having low access to healthy food retailers with incarceration and other covariates in the sample of adults (n 10 390) aged 24-34 years living in urban census tracts in the USA, 2008

\begin{tabular}{|c|c|c|c|c|c|c|c|c|}
\hline & \multicolumn{2}{|r|}{ Model 1} & \multicolumn{2}{|r|}{ Model 2} & \multicolumn{2}{|r|}{ Model 3} & \multicolumn{2}{|c|}{ Model 4} \\
\hline & OR & $95 \% \mathrm{Cl}$ & OR & $95 \% \mathrm{Cl}$ & OR & $95 \% \mathrm{Cl}$ & OR & $95 \% \mathrm{Cl}$ \\
\hline \multicolumn{9}{|l|}{ (a) Food desert (mRFEI $=0$ ) } \\
\hline Prior incarceration & 1.196 & $0.968,1.479$ & $1 \cdot 148$ & $0.938,1.406$ & 1.097 & $0.896,1.343$ & 0.997 & $0.787,1.262$ \\
\hline Age (W4) & & & 0.983 & $0.917,1.053$ & 0.987 & $0.924,1.055$ & 1.032 & $0.935,1.140$ \\
\hline Black & & & 0.955 & $0.617,1.478$ & 0.854 & $0.558,1.305$ & 0.870 & $0.531,1.425$ \\
\hline Hispanic & & & 0.616 & $0.431,0.881$ & 0.624 & $0.438,0.888$ & 0.499 & $0.300,0.832$ \\
\hline Other race & & & 0.712 & $0.422,1.201$ & 0.712 & $0.421,1.205$ & 0.743 & $0.324,1.702$ \\
\hline Male & & & 0.974 & $0.817,1.163$ & 0.985 & $0.824,1.176$ & 0.944 & $0.709,1.258$ \\
\hline Child in home (W4) & & & $1 \cdot 131$ & $0.891,1.437$ & 1.126 & $0.886,1.430$ & 1.150 & $0.799,1.655$ \\
\hline Parent house (W4) & & & 0.998 & $0.770,1.294$ & 0.985 & $0.765,1.268$ & 1.007 & $0.700,1.449$ \\
\hline High school (W4) & & & 0.778 & $0.583,1.040$ & 0.868 & $0.655,1.150$ & 0.829 & $0.540,1.272$ \\
\hline Child abuse (W4) & & & 0.981 & $0.784,1.226$ & 0.975 & $0.772,1.230$ & $1 \cdot 161$ & $0.848,1.589$ \\
\hline Total delinquency (W1) & & & 1.005 & $0.981,1.030$ & 1.004 & $0.979,1.029$ & 1.003 & $0.970,1.038$ \\
\hline Hard drug use (W1) & & & 0.902 & $0.666,1.222$ & 0.908 & $0.667,1.235$ & 0.930 & $0.620,1.394$ \\
\hline Healthy diet (W1) & & & 1.007 & $0.780,1.300$ & 1.003 & $0.778,1.293$ & 1.460 & $0.865,2.464$ \\
\hline Depression (W1) & & & 0.999 & $0.981,1.017$ & 0.997 & $0.979,1.015$ & 0.990 & $0.956,1.026$ \\
\hline Fatalism (W1) & & & 0.945 & $0.860,1.037$ & 0.941 & $0.858,1.032$ & 1.008 & $0.855,1.189$ \\
\hline Concentrated disadvantage (W1) & & & $1 \cdot 189$ & $1.009,1.401$ & 1.084 & $0.951,1.234$ & 1.078 & $0.895,1.299$ \\
\hline Concentrated disadvantage (W4) & & & & & 2.031 & $1.397,2.952$ & 1.966 & $1 \cdot 168,3 \cdot 310$ \\
\hline Sample size & & 10390 & & 10390 & & 10390 & & 2872 \\
\hline \multicolumn{9}{|c|}{ (b) Area with low access to healthy food retailers (mRFEI $<10)$} \\
\hline Prior incarceration & 1.366 & $1.150,1.622$ & 1.323 & $1.117,1.567$ & 1.265 & $1.069,1.498$ & 1.246 & $1.032,1.503$ \\
\hline Age (W4) & & & 0.998 & $0.943,1.056$ & 1.003 & $0.947,1.063$ & 1.034 & $0.952,1.123$ \\
\hline Black & & & 1.255 & $0.966,1.630$ & $1 \cdot 102$ & $0.856,1.417$ & 0.904 & $0.644,1.269$ \\
\hline Hispanic & & & 1.037 & $0.793,1.358$ & 1.047 & $0.804,1.365$ & 0.964 & $0.656,1.416$ \\
\hline Other race & & & 0.798 & $0.559,1.137$ & 0.802 & $0.557,1.156$ & 0.481 & $0.254,0.911$ \\
\hline Male & & & 0.995 & $0.895,1.107$ & 1.007 & $0.904,1.121$ & 0.924 & $0.743,1.150$ \\
\hline Child in home (W4) & & & 0.924 & $0.792,1.077$ & 0.912 & $0.781,1.066$ & 1.007 & $0.720,1.409$ \\
\hline Parent house (W4) & & & 0.969 & $0.787,1.193$ & 0.955 & $0.775,1.178$ & 1.014 & $0.768,1.339$ \\
\hline High school (W4) & & & 0.979 & $0.783,1.224$ & 1.111 & $0.873,1.415$ & 0.906 & $0.649,1.265$ \\
\hline Child abuse (W4) & & & 0.933 & $0.792,1.098$ & 0.923 & $0.779,1.093$ & $1 \cdot 189$ & $0.930,1.521$ \\
\hline Total delinquency (W1) & & & 1.010 & $0.995,1.026$ & 1.009 & $0.993,1.025$ & 1.018 & $0.996,1.041$ \\
\hline Hard drug use (W1) & & & 0.923 & $0.780,1.093$ & 0.931 & $0.786,1.103$ & 0.980 & $0.737,1.303$ \\
\hline Healthy diet (W1) & & & 1.095 & $0.891,1.345$ & 1.096 & $0.891,1.348$ & 0.899 & $0.623,1.298$ \\
\hline Depression (W1) & & & 0.999 & $0.987,1.011$ & 0.997 & $0.986,1.009$ & 0.985 & $0.958,1.013$ \\
\hline Fatalism (W1) & & & 0.984 & $0.913,1.060$ & 0.978 & $0.906,1.056$ & 0.989 & $0.890,1.098$ \\
\hline Concentrated disadvantage (W1) & & & 1.053 & $0.943,1.175$ & 0.942 & $0.844,1.052$ & 0.904 & $0.769,1.062$ \\
\hline Concentrated disadvantage (W4) & & & & & 2.466 & $1.898,3.203$ & 2.397 & $1.610,3.568$ \\
\hline Sample size & & 10390 & & 10390 & & 10390 & & 2872 \\
\hline
\end{tabular}

mRFEI, Modified Retail Food Environment Index; W1, wave I; W4, wave IV.

arrested or convicted of a crime, but not incarcerated. The results shown in Model 4 of Table 3(a) indicate that when the reference category is changed, no association remained between prior incarceration and living in a food desert $(\mathrm{OR}=0.997 ; 95 \% \mathrm{CI} 0.787,1.262)$. The results in Model 4 of Table 3(b) indicate that a positive and significant association remained between prior incarceration and having low access to healthy food retailers ( $\mathrm{OR}=$ $1 \cdot 246 ; 95 \%$ CI 1.032, 1.503).

\section{Discussion}

Using linked data from the Add Health survey and the mRFEI, the present study provides the first assessment of the association between prior incarceration and postrelease access to healthy food retailers. The results demonstrated there while there is no significant association between prior incarceration and living in a food desert, the relationship between prior incarceration and 
low access to healthy food retailers remains even after accounting for confounding characteristics relevant to living in economically disadvantaged areas. Moreover, this effect remains after using a more rigorous comparison group of respondents who had formal contact with the criminal justice system but were not previously incarcerated. This finding is consistent with previous research that suggests areas where formerly incarcerated individuals reside lack critical resources ${ }^{(27)}$. These findings extend this line of research by demonstrating that healthy food retailers are an important resource that are deficient in these communities.

The finding that formerly incarcerated individuals have lower access to healthy food retailers than those who have not been incarcerated may be in part explained by economic deprivation. Healthy food retailers sell food items that are generally more expensive, and since formerly incarcerated individuals reside in more disadvantaged communities, economic hardship could partially explain why healthy food retailers are less likely to operate stores in these areas. Still, although concentrated disadvantage did reduce the association between incarceration and low access to healthy food retailers, the relationship remained even after controlling for concentrated disadvantage of the census tract of residence. One possible explanation for this finding is that there are factors beyond economic deprivation that impact which neighbourhoods formerly incarcerated individuals get access to. Such factors could include legal barriers to housing and discrimination against those with a criminal history. Indeed, past research finds formerly incarcerated individuals face discrimination on the basis of a criminal past ${ }^{(43)}$, and often encounter barriers to obtaining stable housing as a result of discrimination and legal restrictions on housing options $^{(27,28,44-46)}$. Accordingly, a useful area of future research is to assess the degree to which housing restrictions and discrimination contribute to neighbourhood disadvantage and, in turn, reduce access to healthy food retailers among formerly incarcerated individuals.

Further, the finding that formerly incarcerated individuals are more likely to live in areas with low access to healthy food retailers compared with those with an arrest or conviction suggests that incarceration itself, rather than just a criminal record, may be important for understanding disparities in access to food retailers. Because incarceration removes individuals from their neighbourhood of residence, whereas an arrest or conviction does not, it is possible that incarceration may have a greater impact on downward neighbourhood mobility ${ }^{(26)}$. Since the present study was unable to account for neighbourhood quality or composition of the local food retail environment immediately prior to incarceration, this possibility could not be directly assessed. Future research should reassess the link between incarceration and access to food retailers using alternative sources of data that enable an analysis of within-person change in access to food retailers over time.
It is also possible that the presence of formerly incarcerated individuals may create a stigma of local areas that deters businesses from locating in certain neighbourhoods ${ }^{(47)}$. For example, businesses including supermarkets and grocery stores may view these areas as lacking a stable clientele that would be necessary for success $^{(48)}$. Finally, the composition of the food retail environment may be a response to the demand for specific types of foods from local residents. Results from prior research have found formerly incarcerated individuals consume fast foods at higher rates than their nonincarcerated counterparts ${ }^{(25)}$. If so, food retailers may recognize that there is higher demand for unhealthy food items and less demand for healthy food retailers in certain communities, and the disparities in accessibility to healthy food retailers could be reflective of demands for specific types of food items from residents.

The results from the current study suggest several promising areas for future research. First, because approximately 2.6 million children had at least one parent incarcerated in 2012 ${ }^{(49)}$, there may be ripple effects for health and dietary behaviour of children and family members of incarcerated individuals. For instance, prior research finds that incarceration of a parent worsens health behaviours of children, including sleeping and eating patterns ${ }^{(50)}$, and harms children's overall health ${ }^{(51-53)}$. Accordingly, future research that examines the nexus between parental incarceration, access to food retailers, and health and nutrition of children would be greatly valuable. Second, given the size and scope of the incarcerated population in the USA, recent scholarship has identified incarceration as a potential social determinant of health ${ }^{(24)}$, especially for certain demographic groups that are particularly prone to incarceration, such as black men ${ }^{(54)}$. Thus, future research can assess the intersection of incarceration, race and nutrition to more fully understand disparities in health and well-being among minority groups in the USA. Finally, future work should investigate the research question posed in the present study using alternative sources of data. A particularly useful direction is to draw on census tract-level data on incarceration rates to examine the association between aggregate levels of incarceration and the composition of local food retail environments.

\section{Limitations}

There are limitations with the current study that should be expanded upon in future research. First, there may be unobserved factors that confound the relationship between incarceration and nutritional hardships. While Add Health provides a rich set of variables that capture relevant background characteristics, there remain relevant factors that could not be accounted for such as the local retail food environments where respondents lived prior to incarceration or the modes of transportation available to 
an individual. Second, the binary measure of incarceration in the Add Health data misses potentially important information on whether an individual was incarcerated in jail, state or federal prison, or some other type of correctional facility. Third, the mRFEI captures geographic access to food retailers. However, as food environments are complex and multidimensional, future research should consider other aspects of food retail environments. For example, future work can examine the cost of foods within areas. The term 'food mirage' describes the phenomenon in which a community has geographic access to full-service grocery stores, yet food prices are high and therefore foods are inaccessible to many local residents ${ }^{(55)}$. Accordingly, future research should draw on food pricing data to assess the association between incarceration and food affordability ${ }^{(56)}$. Moreover, future work could assess the quality of food sold by local retailers, as prior work finds that even when healthy foods such as fresh produce are available in lower-income communities, they are often of worse quality ${ }^{(57)}$.

Fourth, the null association between prior incarceration and residing in a food desert may be the result of the way in which food deserts are measured. Indeed, the measurement of food deserts varies across studies ${ }^{(13)}$. In the current study, an mRFEI score of 0 conflates areas with no food retailers (either healthy or unhealthy) and areas that are composed of only unhealthy food retailers. Thus, the null findings related to food deserts could potentially be related to the confounding of these geographic areas. Future research should continue to investigate the most appropriate measurements of food deserts, as well as assess the relationship between incarceration and access to food retailers with alternative sources of data. Finally, it is important to note that given the USA has an incarceration rate approximately five to ten times higher than other developed countries ${ }^{(19)}$, the findings of this research should not be generalized to contexts outside the USA. However, future research that considers the relationship between incarceration and access to healthy food retailers in other countries would be valuable.

\section{Conclusion}

Areas with a high ratio of unhealthy food retailers relative to healthy food retailers are associated with obesity ${ }^{(58)}$ and unhealthy nutrition ${ }^{(59)}$. Accordingly, the finding that formerly incarcerated individuals are more likely to reside in areas with a greater ratio of unhealthy to healthy food retailers may carry negative implications for health and dietary behaviour of formerly incarcerated individuals. Areas with higher rates of formerly incarcerated residents could benefit from efforts to expand access to healthy food retailers. One option is to extend policy initiatives to these areas such as the Healthy Food Financing Initiative (HFFI), a federal programme that awards loans and grants targeted at developing and equipping food retailers to sell healthy foods in underserved communities across the USA ${ }^{(60)}$. Additionally, city planners and policy makers can implement incentives to attract more grocery stores to areas with few healthy food retailers, while also placing zoning restrictions on fast-food restaurants and convenience stores. This two-pronged approach can promote better diet and health by improving the relative balance of healthy to unhealthy food retailers in local communities ${ }^{(58)}$. Finally, mobile feeding programmes can be expanded to target areas with larger populations of formerly incarcerated individuals. The purpose of mobile feeding programmes is to transport food to individuals, rather than require individuals to access locations to obtain food. Such a programme can be useful in areas with higher levels of crime and incarceration as they do not require individuals to travel through communities that may be prone to violence in order to access food ${ }^{(61)}$. Still, future research should continue to investigate the association between incarceration and aspects of local food retail environments, as well as how food retail environments influence health and dietary behaviour of formerly incarcerated individuals.

\section{Acknowledgements}

Acknowledgements: Special thanks are due to Lauren Porter who provided invaluable feedback on earlier drafts. The author would also like to thank Jean McGloin, Brian Johnson, James Lynch and Elaine Anderson who offered helpful comments; and the anonymous reviewers for their helpful comments. This research uses data from Add Health, a programme project directed by Kathleen Mullan Harris and designed by J. Richard Udry, Peter S. Bearman and Kathleen Mullan Harris at the University of North Carolina at Chapel Hill, and funded by grant P01-HD31921 from the Eunice Kennedy Shriver National Institute of Child Health and Human Development, with cooperative funding from twenty-three other federal agencies and foundations. Special acknowledgment is due Ronald R. Rindfuss and Barbara Entwisle for assistance in the original design. Information on how to obtain the Add Health data files is available on the Add Health website (http://www. cpc.unc.edu/addhealth). No direct support was received from grant P01-HD31921 for this analysis. Financial support: This study received no specific grant from any funding agency in the public, commercial or not-for-profit sectors. Conflict of interest: There is no conflict of interest. Authorship: A.T. collected the data, performed all analyses and drafted the entire manuscript. Ethics of human subject participation: The University of Maryland Institutional Review Board determined that this submission does not constitute human subject research as defined by federal regulation 45 CFR 46.101(b) and was exempt from institutional review board approval. 


\section{References}

1. Ver Ploeg M (2012) Access to Affordable and Nutritious Food: Updated Estimates of Distance to Supermarkets Using 2010 Data. Washington, DC: US Department of Agriculture, Economic Research Service.

2. Furey S, Strugnell C \& McIlveen MH (2001) An investigation of the potential existence of 'food deserts' in rural and urban areas of Northern Ireland. Agric Hum Values 18, $447-457$.

3. Larson NI, Story MT \& Nelson MC (2009) Neighborhood environments: disparities in access to healthy foods in the US. Am J Prev Med 36, 74-81.

4. Moore LV, Diez Roux AV, Nettleton JA et al. (2008) Associations of the local food environment with diet quality - a comparison of assessments based on surveys and geographic information systems: the multiethnic study of atherosclerosis. Am J Epidemiol 167, 917-924.

5. Morland K, Diez Roux AV \& Wing S (2006) Supermarkets, other food stores, and obesity: the atherosclerosis risk in communities study. Am J Prev Med 30, 333-339.

6. Inagami S, Cohen DA, Finch BK et al. (2006) You are where you shop: grocery store locations, weight, and neighborhoods. Am J Prev Med 31, 10-17.

7. Powell LM, Auld MC, Chaloupka FJ et al. (2007) Associations between access to food stores and adolescent body mass index. Am J Prev Med 33, 4 Suppl., S301-S307.

8. Wang MC, Cubbin C, Ahn D et al. (2008) Changes in neighbourhood food store environment, food behaviour and body mass index, 1981-1990. Public Health Nutr 11, 963-970.

9. Boone-Heinonen J, Gordon-Larsen P, Kiefe CI et al. (2011) Fast-food restaurants and food stores: longitudinal associations with diet in young to middle-aged adults: the CARDIA study. Arch Intern Med 171, 1162-1170.

10. Moore LV, Diez Roux AV, Nettleton JA et al. (2009) Fastfood consumption, diet quality, and neighborhood exposure to fast food: the multi-ethnic study of atherosclerosis. Am J Epidemiol 170, 29-36.

11. Maddock J (2004) The relationship between obesity and the prevalence of fast-food restaurants: state-level analysis. $A m J$ Health Promot 19, 137-143.

12. Mehta NK \& Chang VW (2008) Weight status and restaurant availability: a multilevel analysis. Am J Prev Med 34, 127-133.

13. Walker RE, Keane CR \& Burke JG (2010) Disparities and access to healthy food in the United States: a review of food deserts literature. Health Place 16, 876-884.

14. Rose D, Bodor JN, Swalm C et al. (2009) Deserts in New Orleans? Illustrations of Urban Food Access and Implications for Policy. Ann Arbor, MI: University of Michigan National Poverty Center/US Department of Agriculture, Economic Research Service.

15. Ver Ploeg M, Breneman V, Farrigan T et al. (2009) Access to Affordable and Nutritious Food - Measuring and Understanding Food Deserts and Their Consequences: Report to Congress. Washington, DC: US Department of Agriculture, Economic Research Service.

16. Hilmers A, Hilmers DC \& Dave J (2012) Neighborhood disparities in access to healthy foods and their effects on environmental justice. Am J Public Health 102, 1644-1654.

17. Morland K, Wing S \& Diez Roux A (2002) The contextual effect of the local food environment on residents' diets: the atherosclerosis risk in communities study. Am J Public Health 92, 1761-1768.

18. Zenk SN, Schulz AJ, Israel BA et al. (2005) Neighborhood racial composition, neighborhood poverty, and the spatial accessibility of supermarkets in metropolitan Detroit. $\mathrm{Am} \mathrm{J}$ Public Health 95, 660-667.
19. Travis J, Western B \& Redburn FS (2014) The Growth of Incarceration in the United States: Exploring Causes and Consequences. Washington, DC: National Academies Press.

20. Uggen C, Manza J \& Thompson M (2006) Citizenship, democracy, and the civic reintegration of criminal offenders. Ann Am Acad Polit Soc Sci 605, 281-310.

21. Carson AE (2018) Prisoners in 2016. Washington, DC: US Bureau of Justice Statistics.

22. Zeng Z (2018) Jail Inmates in 2016. Washington, DC: US Bureau of Justice Statistics.

23. Wakefield S \& Uggen C (2010) Incarceration and stratification. Annu Rev Sociol 36, 387-406.

24. Wildeman C \& Wang EA (2017) Mass incarceration, public health, and widening inequality in the USA. Lancet $\mathbf{3 8 9}$, $1464-1474$.

25. Porter LC (2014) Incarceration and post-release health behavior. J Health Soc Behav 55, 234-249.

26. Massoglia M, Firebaugh G \& Warner C (2013) Racial variation in the effect of incarceration on neighborhood attainment. Am Soc Rev 78, 142-165.

27. Harding DJ, Wyse JJ, Dobson C et al. (2014) Making ends meet after prison. J Policy Anal Manage 33, 440-470.

28. Harding DJ, Morenoff JD \& Herbert CW (2013) Home is hard to find: neighborhoods, institutions, and the residential trajectories of returning prisoners. Ann Am Acad Polit Soc Sci 647, 214-236.

29. Caspi CE, Sorensen G, Subramanian SV et al. (2012) The local food environment and diet: a systematic review. Health Place 18, 1172-1187.

30. Michimi A \& Wimberly MC (2010) Associations of supermarket accessibility with obesity and fruit and vegetable consumption in the conterminous United States. Int J Health Geogr 9, 49 .

31. Moore LV \& Diez Roux AV (2006) Associations of neighborhood characteristics with the location and type of food stores. Am J Public Health 96, 325-331.

32. Lytle LA \& Sokol RL (2017) Measures of the food environment: a systematic review of the field, 2007-2015. Health Place 44, 18-34.

33. Harris KM \& Udry JR (2008) National Longitudinal Study of Adolescent Health (Add Health), 1994-2008. Chapel Hill, NC: Inter-university Consortium for Political and Social Research.

34. Centers for Disease Control and Prevention (2011) Census Tract Level State Maps of the Modified Retail Food Environment Index (mRFEI). Atlanta, GA: US Department of Health and Human Services.

35. Mason KE, Bentley RJ \& Kavanagh AM (2013) Fruit and vegetable purchasing and the relative density of healthy and unhealthy food stores: evidence from an Australian multilevel study. J Epidemiol Community Health 67, 231-236.

36. Clary CM, Ramos Y, Shareck M et al. (2015) Should we use absolute or relative measures when assessing foodscape exposure in relation to fruit and vegetable intake? Evidence from a wide-scale Canadian study. Prev Med $\mathbf{7 1}$, 83-87.

37. Santorelli ML \& Okeke JO (2017) Evaluating community measures of healthy food access. $J$ Community Health $\mathbf{4 2}$, 991-997.

38. Koh K, Grady SC \& Vojnovic I (2015) Using simulated data to investigate the spatial patterns of obesity prevalence at the census tract level in metropolitan Detroit. Appl Geogr 62, 19-28.

39. Luan H, Law J \& Quick M (2015) Identifying food deserts and swamps based on relative healthy food access: a spatiotemporal Bayesian approach. Int J Health Geogr 14, 37.

40. Allison P (2012) When can you safely ignore multicollinearity? Statistical Horizons. https://statisticalhorizons. com/multicollinearity (accessed September 2018). 
41. Karlson KB, Holm A \& Breen R (2012) Comparing regression coefficients between same-sample nested models using logit and probit: a new method. Sociol Methodol 42, 286-313.

42. Mood C (2010) Logistic regression: why we cannot do what we think we can do, and what we can do about it. Eur Sociol Rev 26, 67-82.

43. Pager D (2003) The mark of a criminal record. Am J Sociol 108, 937-975.

44. Geller A \& Curtis MA (2011) A sort of homecoming: incarceration and the housing security of urban men. Soc Sci Res 40, 1196-1213.

45. Herbert CW, Morenoff JD \& Harding DJ (2015) Homelessness and housing insecurity among former prisoners. RSF 1, 44-79.

46. Travis J (2005) But They All Come Back: Facing the Challenges of Prisoner Reentry. Washington, DC: The Urban Institute.

47. Fagan J, West V \& Holland J (2003) Reciprocal effects of crime and incarceration in New York City neighborhoods. Fordham Urban Law J 30, 1551-1602.

48. Pothukuchi K (2005) Attracting supermarkets to inner-city neighborhoods: economic development outside the box. Econ Dev Q 19, 232-244.

49. Sykes B \& Pettit B (2014) Mass incarceration, family complexity, and the reproduction of childhood disadvantage. Ann Am Acad Polit Soc Sci 654, 127-129.

50. Jackson DB \& Vaughn MG (2017) Parental incarceration and child sleep and eating behaviors. J Pediatrics 185, 211-217.

51. Turney K (2014) Stress proliferation across generations? Examining the relationship between parental incarceration and childhood health. J Health Soc Behav 55, 302-319.
52. Wildeman C \& Muller C (2012) Mass imprisonment and inequality in health and family life. Annu Rev Law Soc Sci $\mathbf{8}$, $11-30$.

53. Wildeman C, Goldman AW \& Turney K (2018) Parental incarceration and child health in the United States. Epidemiol Rev 40, 146-156.

54. Nowotny KM \& Kuptsevych-Timmer A (2018) Health and justice: framing incarceration as a social determinant of health for Black men in the United States. Sociol Compass 12, e12566.

55. Short A, Guthman J \& Raskin S (2007) Food deserts, oases, or mirages? Small markets and community food security in the San Francisco Bay Area. J Planning Educ Res 26, 352-364.

56. Drewnowski A, Aggarwal A, Hurvitz PM et al. (2012) Obesity and supermarket access: proximity or price? Am J Public Health 102, 74-80.

57. Andreyeva T, Blumenthal DM, Schwartz MB et al. (2008) Availability and prices of foods across stores and neighborhoods: the case of New Haven, Connecticut. Health Aff (Millwood) 27, 1381-1388.

58. Cooksey-Stowers K, Schwartz MB \& Brownell KD (2017) Food swamps predict obesity rates better than food deserts in the United States. Int J Environ Res Public Health 14, 1366.

59. Hager ER, Cockerham A, O'Reilly N et al. (2017) Food swamps and food deserts in Baltimore City, MD, USA: associations with dietary behaviours among urban adolescent girls. Public Health Nutr 20, 2598-2607.

60. Flournoy R (2011) Healthy Food, Healthy Communities: Promising Strategies to Improve Access to Fresh, Healthy Food and Transform Communities. Oakland, CA: PolicyLink.

61. Jackson DB, Newsome J, Vaughn MG et al. (2018) Considering the role of food insecurity in low self-control and early delinquency. J Crim Just 56, 127-139. 